\title{
Proprioceptive Information from the Pinna Provides Somatosensory Input to Cat Dorsal Cochlear Nucleus
}

\author{
Patrick O. Kanold and Eric D. Young \\ The Center for Hearing Sciences and Department of Biomedical Engineering, The Johns Hopkins University School of \\ Medicine, Baltimore, Maryland 21205
}

\begin{abstract}
The dorsal cochlear nucleus (DCN) is a second-order auditory structure that also receives nonauditory information, including somatosensory inputs from the dorsal column and spinal trigeminal nuclei. Here we investigate the peripheral sources of the somatosensory inputs to DCN. Electrical stimulation was applied to cervical nerves $\mathrm{C} 1-\mathrm{C} 8$, branches of $\mathrm{C} 2$, branches of the trigeminal nerve, and hindlimb nerves. The largest evoked potentials in the DCN were produced by $\mathrm{C} 2$ stimulation and by stimulation of its branches that innervate the pinna. Electrical stimulation of C2 produced a pattern of inhibition and excitation of DCN principal cells comparable with that seen in previous studies with stimulation of the primary somatosensory nuclei, suggesting that the same pathway was activated. Because C2 contains both proprioceptive and cutaneous fibers, we applied
\end{abstract}

peripheral somatosensory stimulation to identify the effective somatosensory modalities. Only stimuli that activate pinna muscle receptors, such as stretch or vibration of the muscles connected to the pinna, were effective in driving DCN units, whereas cutaneous stimuli such as light touch, brushing of hairs, and stretching of skin were ineffective. These results suggest that the largest somatosensory inputs to the DCN originate from muscle receptors associated with the pinna. They support the hypothesis that a role of the DCN in hearing is to coordinate pinna orientation to sounds or to support correction for the effects of pinna orientation on sound-localization cues.

Key words: auditory; somatosensory; dorsal cochlear nucleus; cat; pinna; multisensory; sound localization
The output neurons of the dorsal cochlear nucleus (DCN) are sensitive to both auditory and somatosensory stimuli (Saadé et al., 1989; Young et al., 1995), suggesting a cross-modal associative role for the DCN. The somatosensory inputs to the DCN originate predominantly from the ipsilateral dorsal column and spinal trigeminal nuclei (abbreviated MSN for medullary somatosensory nuclei) (Itoh et al., 1987; Weinberg and Rustioni, 1987; Wright and Ryugo, 1996). Electrical stimulation in the cat MSN yields strong inhibition and weak excitation of DCN principal cells (Young et al., 1995; Davis et al., 1996). The strongest DCN responses were obtained when the MSN was stimulated at a position in the somatotopic map of the MSN at which the ipsilateral pinna and adjacent regions of the head and neck are represented (Young et al., 1995). Cartwheel cells, which are inhibitory interneurons in the superficial layer of the DCN, are excited by MSN stimulation and are thought to convey much of the somatosensory inhibition to principal cells (Davis and Young, 1997).

Conflicting results about the peripheral receptive fields of the somatosensory projection to DCN have been reported. We found in previous studies that manipulation of the pinna produced DCN principal cell responses, consistent with the electrical stimulation results (Young et al., 1995). In contrast, Saadé et al. (1989) found receptive fields spread widely over the body. In both studies, the surgical preparation caused extensive damage to the head region,

\footnotetext{
Received June 20, 2001; revised July 24, 2001; accepted July 26, 2001.

This work was supported by National Institute on Deafness and Other Communication Disorders Grant DC00979. We thank Israel Nelken, Kevin Davis, Ian Bruce, Brad May, Mike Heinz, Dan Butts, and two anonymous reviewers for constructive comments on this manuscript.

Correspondence should be addressed to Eric D. Young, 505 Traylor Building, Johns Hopkins University School of Medicine, 720 Rutland Avenue, Baltimore, MD 21205. E-mail: eyoung@bme.jhu.edu.

Copyright (C) 2001 Society for Neuroscience $\quad 0270-6474 / 01 / 217848-11 \$ 15.00 / 0$
}

including the pinna and extending to the first few cervical nerves. Given this damage, it is difficult to determine the receptive fields and modalities of the somatosensory projection to the DCN.

The possibility that somatosensory inputs to the DCN carry information from the pinna is intriguing given the role of the cat pinna in producing sound-localization cues (Musicant et al., 1990; Rice et al., 1992) and the evidence that the DCN plays a role in processing those cues (Sutherland et al., 1998; May, 2000; Young and Davis, 2001). The goal of this study was to investigate the peripheral pathways associated with the somatosensory inputs to the DCN.

The pinna and the neck of cats are innervated by the upper cervical nerves $(\mathrm{C} 1-\mathrm{C} 3)$, which project to the MSN (Hekmatpanah, 1961; Abrahams et al., 1984a,b). We electrically stimulated cervical dorsal roots and peripheral nerves to identify the anatomical source of the projection of the MSN to the DCN. We found that $\mathrm{C} 2$, particularly its branches innervating the pinna, provides the major spinal source of somatosensory input to the DCN. To identify the modality and peripheral receptive fields of the DCN-projecting neurons, we applied cutaneous and musclespecific stimuli to a novel preparation with the entire ipsilateral side of the head and neck intact, allowing access to the pinna in a completely undamaged state. We found strong responses to stimuli that should activate muscle receptors, such as vibration and muscle stretch, for muscles connected to the pinna, but no responses to cutaneous somatosensory modalities, such as touch and hair receptors.

\section{MATERIALS AND METHODS}

Data were obtained from 26 adult cats weighing 3-4 kg with infectionfree ears and clear tympanic membranes. The experimental protocol was approved by the Johns Hopkins Animal Care and Use Committee (protocol number CA96M43). 
Surgical preparation. Cats were premedicated with xylazine ( $2 \mathrm{mg}, \mathrm{i} . \mathrm{m}$.) and atropine $(0.1 \mathrm{mg}, \mathrm{i} . \mathrm{m}$.) and anesthetized with ketamine (initial dose of $40 \mathrm{mg} / \mathrm{kg}$, i.m.; supplemental doses of $15 \mathrm{mg} / \mathrm{kg}$, i.v.). Body temperature (measured rectally) was maintained at $38.5^{\circ} \mathrm{C}$. The head was fixed in a nose clamp with bite bar. The scalp was incised along the midline, the right temporalis muscle was reflected, and the right external acoustic meatus was removed. Cats were decerebrated by performing a craniotomy over the right cortex, aspirating enough cortex to expose the superior colliculus, and aspirating through the brainstem between the superior colliculus and the thalamus. After the decerebration, no additional anesthetic was given. The cat was monitored for voluntary movements, indicating an incomplete decerebration, for at least $4 \mathrm{hr}$ and then paralyzed (gallamine triethiodide, $10 \mathrm{mg} / \mathrm{hr}$, i.v.) and artificially respired at an end-tidal $\mathrm{CO}_{2}$ of $4 \%$.

Two preparations were used. In one (exposed DCN), access to the left DCN was gained directly from the ipsilateral side by removing the occipital condyle and drilling a hole in the skull lateral to the foramen magnum, exposing the DCN. This preparation was used for experiments in which the cervical nerves and their branches were stimulated. Substantial damage was done to the skin ipsilateral to the recording site, but care was taken to preserve the peripheral branches of $\mathrm{C} 2$ and their blood supply in the pinna and adjacent tissue. The head was fixed in the recording position, $37^{\circ}$ nose down with respect to stereotaxic horizontal, using a headpiece and two ear bars. For the second preparation (intact head), all skin and other tissue on the left side of the head and neck were maintained intact. The head was fixed in the same recording position by a custom head holder attached entirely to the right side of the head and an ear bar in the right ear. The left DCN was approached from the contralateral (right) side by aspirating part of the cerebellum and inserting the recording electrode into the DCN along a track parallel to the pyramidal cell layer and approximately parallel to the frontal plane (as by Spirou et al., 1993). Because of the frequency organization of the DCN, this approach records predominantly from units with high best frequencies $(>20 \mathrm{kHz})$. At the end of the experiment, the cat was killed with an overdose of pentobarbital sodium $(100 \mathrm{mg} / \mathrm{kg}$ to effect).

Recording. The preparation was placed in a sound-attenuating chamber. Recordings were done with platinum-iridium metal electrodes. The signal from the recording electrode was amplified in two channels. (1) Evoked potentials (EPs) were low-pass filtered at $5 \mathrm{kHz}$ and digitized at $10 \mathrm{kHz}$, with 200-400 traces being averaged. (2) Single-unit action potentials were filtered $(\sim 100 \mathrm{~Hz}$ to $6 \mathrm{kHz})$ and detected using a variable-threshold Schmitt trigger. Electrodes were advanced into the DCN while presenting $50-200 \mathrm{msec}$ search stimuli once per $250 \mathrm{msec}$ or once per $1 \mathrm{sec}$ at the best frequency (BF) of the background activity or 50-200 msec noise bursts. In EP studies, the electrode position in the DCN was fixed, with no isolated single units. The EP amplitude in DCN varies slowly with recording depth, but the shape of the EP waveform changes hardly at all (Young et al., 1995). Thus, the EP at any recording site in DCN is typical of the whole nucleus. EPs were recorded at one site in each cat; amplitudes were compared across cats by normalizing to the maximum EP recorded in the same cat.

Acoustic stimuli. In the exposed-DCN preparation, a closed sound system was connected by a hollow ear bar to the left ear. In the intacthead preparation, a speaker (Radio Shack model 40-1377) was suspended $\sim 70 \mathrm{~cm}$ above the cat's head, where the head-related transfer functions are reasonably flat (Rice et al., 1992). The sound systems were used for unit typing only and were not calibrated. Once a unit was isolated, its BF was determined and its responses were classified as type I/III, II, III, or IV (Young et al., 1995), based on the appearance of inhibitory and excitatory responses in BF rate-level functions and noise rate-level functions. Units in the superficial DCN that showed complex spike bursts were assumed to be cartwheel cells (Zhang and Oertel, 1993; Manis et al., 1994). They are called "complex-spiking neurons" in this paper. Results will be shown only for the DCN principal cell types (III and IV) (Young, 1980) and for complex-spiking neurons.

Peripheral electrical stimulation. The exposed-DCN preparation was used to determine the spinal source of the somatosensory input to the DCN. Nerve trunks at the roots of the cervical nerves (C1-C8), as well as branches of nerve $\mathrm{C} 2$ in the head and neck region, were isolated and covered with mineral oil to prevent drying. The branches were electrically stimulated (bipolar stimulating electrodes, four biphasic stimulating pulses of $100 \mu \mathrm{sec}$ per phase, interpulse interval of $50 \mathrm{msec}$, repeated once per second, stimulation currents of $0.05-15 \mathrm{~mA}$ ), and the resulting EPs and single-unit responses in the DCN were recorded. Multiple stimulus amplitudes were tested in each nerve with the goal of stimulating the whole nerve trunk, as judged by saturation of the observed EP. Saturation of the EP usually occurred with stimulus currents of $0.5-1.5 \mathrm{~mA}$.

Somatosensory characterization. The intact-head preparation was used to determine the peripheral somatosensory receptive fields of DCN single units. These tests were performed in the absence of intentional acoustic stimulation so that the DCN units were firing spontaneously or in the presence of continuous background noise to mask sounds produced by the exploration. A variety of stimuli (brushing, touching, pinching, skin stretch, tapping, displacing hairs, moving joints, and deep pressure) were manually applied to various parts of the body. The responses of DCN units were monitored and classified as excitatory or inhibitory if the firing rate increased or decreased by $>2$ SDs from the spontaneous rate.

To generate repeatable muscle-stretch stimuli, sinusoidal pulling (one to four cycles at 10 or $20 \mathrm{~Hz}$, presented every $1-5 \mathrm{sec}$ ) of the pinna was used. This stimulus stretches the muscles that normally move the pinna medialward (musculus auricularis superioris, musculus levator auris longus, and musculus intermedius scutulorum) (Reighard and Jennings, 1901). These frequencies and durations were chosen to approximate the activity evoked with four-pulse electrical stimulation of the peripheral nerves, as described above. The mechanical stimulator was an encased and dampened loudspeaker with an attached plastic probe $(8 \mathrm{~mm}$ diameter, $50 \mathrm{~mm}$ length). The probe was attached to the pinna by $\sim 1-2 \mathrm{~cm}$ of surgical yarn glued to the tip of the pinna with Super Glue. The yarn was coated with Super Glue to provide a stiffer coupling between pinna and probe. The pinna was initially pulled laterally to provide a slight basal stretch of the superior pinna muscles. Because DCN principal cells are very sensitive to wideband acoustic stimuli, the pinna was shaved to eliminate the noise produced by hairs during movement.

Vibratory stimuli were used to stimulate muscle afferents selectively. Muscle afferents are sensitive to vibration at frequencies of $50-300 \mathrm{~Hz}$ applied to the muscle tendon, a stimulus that has been used frequently to identify IA afferents (Echlin and Fessard, 1938; Kuffler, et al., 1951; Granit and Henatsch, 1956; Bianconi and Van Der Meulen, 1963; Crowe and Matthews, 1964). Vibration over a similar frequency range was applied perpendicularly to the belly of the superior pinna muscles (musculus auricularis superioris and musculus levator auris longus). The vibrator was a plastic probe ( $8 \mathrm{~mm}$ diameter, $120 \mathrm{~mm}$ length) attached to the cone of an encased and dampened loudspeaker. The vibrator was applied with sufficient pressure to stretch the muscle. To control for acoustic artifacts and other modes of stimulation, the tests were repeated with the probe moved a few millimeters so that it did not contact the muscle. Vibration was applied in bursts of $250 \mathrm{msec}$ duration presented once per second.

Data are presented either as means \pm SD or as medians; group means are compared using a Student's $t$ test, and medians are compared with a Wilcoxon rank sum test.

\section{RESULTS}

\section{Which cervical nerves contribute to the evoked potentials seen in DCN?}

To define the spinal sources of somatosensory input to the DCN, we stimulated the dorsal roots of the cervical nerves $\mathrm{C} 1-\mathrm{C} 8$ close to the spinal cord, using the exposed-DCN preparation. The DCN recording electrode was fixed in position while the nerves were sequentially stimulated. Figure 1 shows EP recordings from one animal. The largest EPs were generated by stimulation of $\mathrm{C} 2$, with smaller potentials from some other nerves, especially C3, C7, and C8. The EPs had the same shape and general appearance as those evoked in DCN by stimulation of MSN (Davis et al., 1996). During maximal C2 stimulation, EPs ranged from 0.04 to 0.17 $\mathrm{mV}$ in different animals, which is comparable with the range seen with MSN stimulation.

To compare the responses to $\mathrm{C} 1-\mathrm{C} 8, \mathrm{EP}$ amplitudes were normalized to the largest EP in the same animal (always $\mathrm{C} 2 ; n=$ 5). The stimulus current in each cat was held constant at a level that produced saturation of EP amplitudes in all nerves (usually $<1.5 \mathrm{~mA}$ ), except for two cats in which saturation was not ob- 

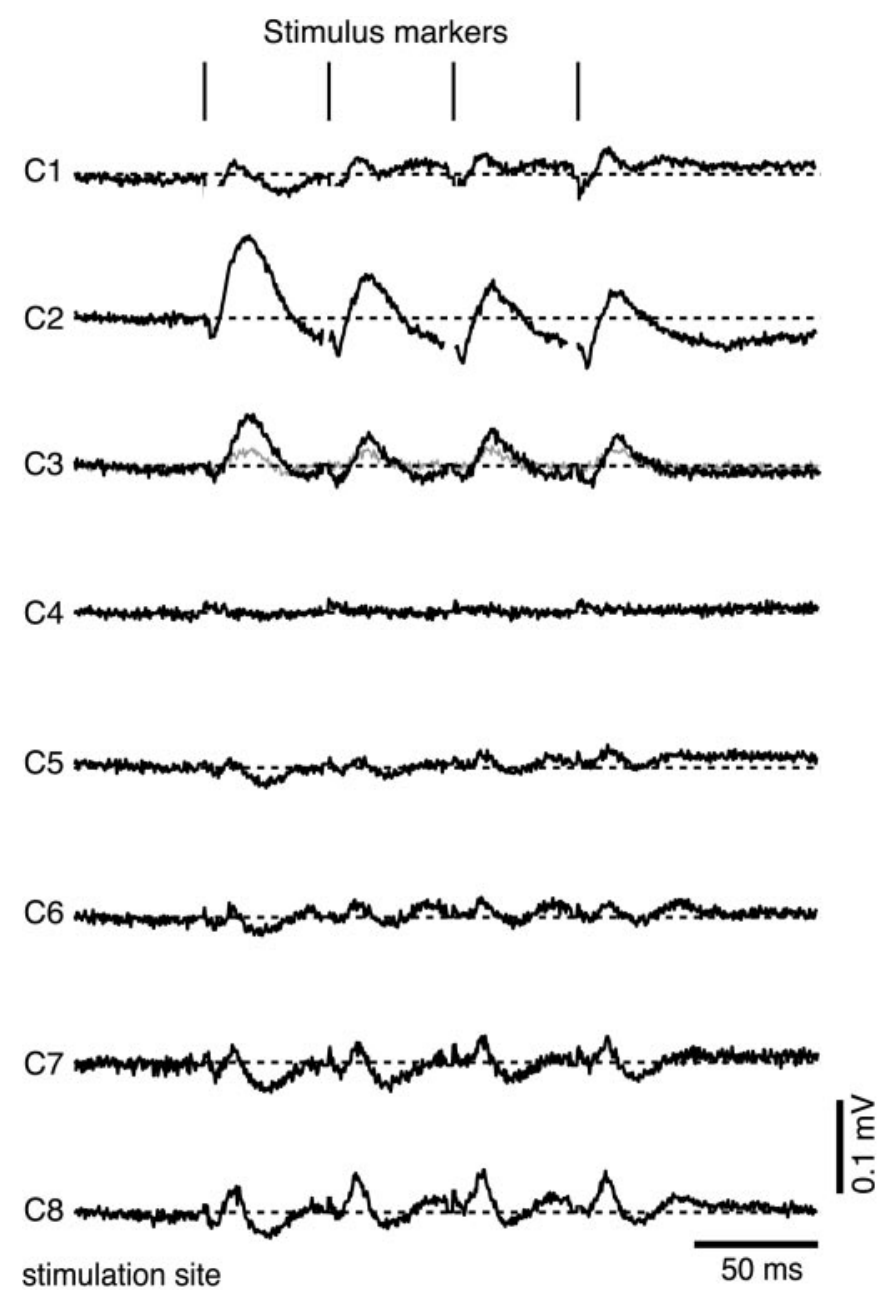

Figure 1. EPs in DCN during $0.5 \mathrm{~mA}$ electrical stimulation of cervical nerves $\mathrm{C} 1-\mathrm{C} 8$ close to their respective dorsal root ganglia; all data are from the same preparation. The stimulation site is indicated to the left of each trace. The stimulus markers at the top show the electrical shock times (50 msec interstimulus spacing). Stimulus artifacts have been partially zeroed. Each trace represents the average of 200 repetitions. The gray trace in $\mathrm{C} 3$ shows the $\mathrm{C} 3 \mathrm{EP}$ after $\mathrm{C} 2$ had been sectioned.

served for $\mathrm{C} 3$, discussed below. If no EP was observed, as for C4 in Figure 1, higher current levels (up to $15 \mathrm{~mA}$ ) were tested. Figure $2 A$ shows the relative sizes of the EPs across five cats, as median values (bars) and ranges. The largest EPs were produced by $\mathrm{C} 2$ stimulation; the median EPs from $\mathrm{C} 1$ and $\mathrm{C} 3-\mathrm{C} 8$ were significantly smaller ( $p<0.002$; except for $\mathrm{C} 1$ and $\mathrm{C} 8, p<0.004)$.

In most cats (four of five), stimulating $\mathrm{C} 3$ resulted in large EPs in the DCN (Fig. $2 A$, column 3). In two cats, the C3 EP did not saturate, although the current was raised by at least a factor of 2 , to a level clearly supramaximal for other nerves. This increase resulted in large increases of the $\mathrm{C} 3$-evoked EP (the maximal EP amplitudes obtained are plotted in Fig. $2 A$ ). It is likely that the increased C3 EP is attributable to stimulus spread to $\mathrm{C} 2$ through anastomoses, because branches of $\mathrm{C} 2$ join $\mathrm{C} 3$ at a proximal location (Reighard and Jennings, 1901; Getty, 1975). To investigate this possibility, $\mathrm{C} 2$ was cut in three cases in which stimulation of C3 gave relatively large responses (two of these are shown with open symbols in column 3 of Fig. 2A). The traces for one such experiment are shown in Figure 1; cutting $\mathrm{C} 2$ in this cat significantly reduced the size of the $\mathrm{C} 3 \mathrm{EP}$, as shown by the gray trace
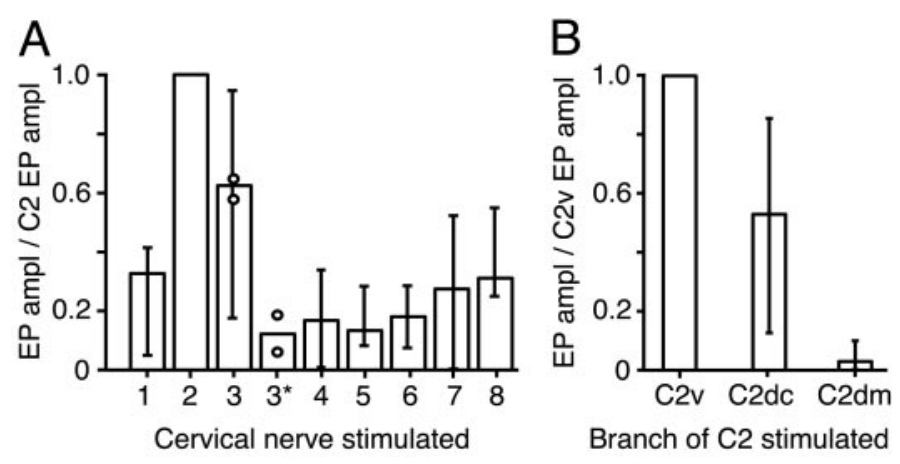

Figure 2. Comparison of EP amplitudes from various peripheral nerves. $A$, EP amplitude during the first stimulus pulse for cervical nerves $\mathrm{C} 1-\mathrm{C} 8$ relative to the amplitude for $\mathrm{C} 2$ in the same cat. Data from five cats are shown, except that one cat's data for $\mathrm{C} 1$ and $\mathrm{C} 8$ were not used because of stimulus artifacts. Each bar shows the median relative EP amplitude, with the total range of the data shown by the lines. $\mathrm{C} 2$ stimulation always resulted in the largest EP. The open circles in the 3 and $3 *$ columns show data from two cats in which the C3 amplitude was measured before (3) and after $\left(3^{*}\right)$ cutting C2. $B$, Relative EP amplitudes from three branches of $\mathrm{C} 2$ in six cats (different cats from $A$, except for 1 case). C2dm was not studied in two cats. The EPs are normalized to the EP of $\mathrm{C} 2 \mathrm{v}$ in each cat. The largest EPs are seen in branches of C2 that innervate the pinna.

in the $C 3$ row. The $\mathrm{C} 3$ amplitudes with $\mathrm{C} 2$ cut are plotted in column $3 *$ in Figure $2 A$ for two cats. A similar result was obtained in one additional cat in which only nerves $\mathrm{C} 2$ and $\mathrm{C} 3$ were stimulated: the $\mathrm{C} 3 / \mathrm{C} 2$ ratio was 0.89 before cutting $\mathrm{C} 2$ and 0.11 afterward. These results suggest that the large $\mathrm{C} 3$ responses were caused by spread of current to $\mathrm{C} 2$.

The possibility of stimulus spread to $\mathrm{C} 2$ from nerves other than $\mathrm{C} 3$, especially $\mathrm{C} 1$, which is very small, cannot be ruled out. However, the pattern of amplitudes shown in Figure $2 A$ is not consistent with all effects being attributable to stimulus spread. In particular, amplitudes were larger in $\mathrm{C} 7$ and $\mathrm{C} 8$ than in $\mathrm{C} 4-\mathrm{C} 6$ in four of five cats, which is the opposite of the result expected from simple current spread. In addition, the results in Figure $2 A$ are consistent with those in Figure 10 of a previous paper (Young et al., 1995) in which substantial EPs were observed in DCN when stimulation was applied to nonpinna regions of the MSN somatotopic map.

Outside of $\mathrm{C} 2$ and $\mathrm{C} 3$, the largest EP amplitudes were obtained at $\mathrm{C} 7$ and $\mathrm{C} 8$ (up to $50-55 \%$ of the C2 EP in individual cases). Stimulation of the median nerve (which is derived from C7 and C8) in the ipsilateral forearm produced EPs that were similar in size to the potentials observed with $\mathrm{C} 7 / \mathrm{C} 8$ stimulation $(n=2$; data not shown). The source of the high variability of the C7 EP, especially the fact that virtually no C7 EPs were observed in two cats, is unclear. The fact that raising the stimulation amplitude in these two cats was not sufficient to evoke an EP in C7 whereas stimulation of C8 (which is of comparable size) gave a robust EP suggests that there might be large differences between cats in the extent of contributions from C7 to DCN.

In two cats, we stimulated the mandibular branch of the trigeminal nerve, which innervates the rostral pinna and adjacent areas of the face, at a site ventral to the pinna close to the emergence of the nerve from the skull. The stimulation resulted in EPs of 6 and $30 \%$ of the C2 EP ( $n=2$; data not shown). Stimulation of ipsilateral hindlimb nerves did not produce EPs in the DCN ( $n=2$; data not shown). 

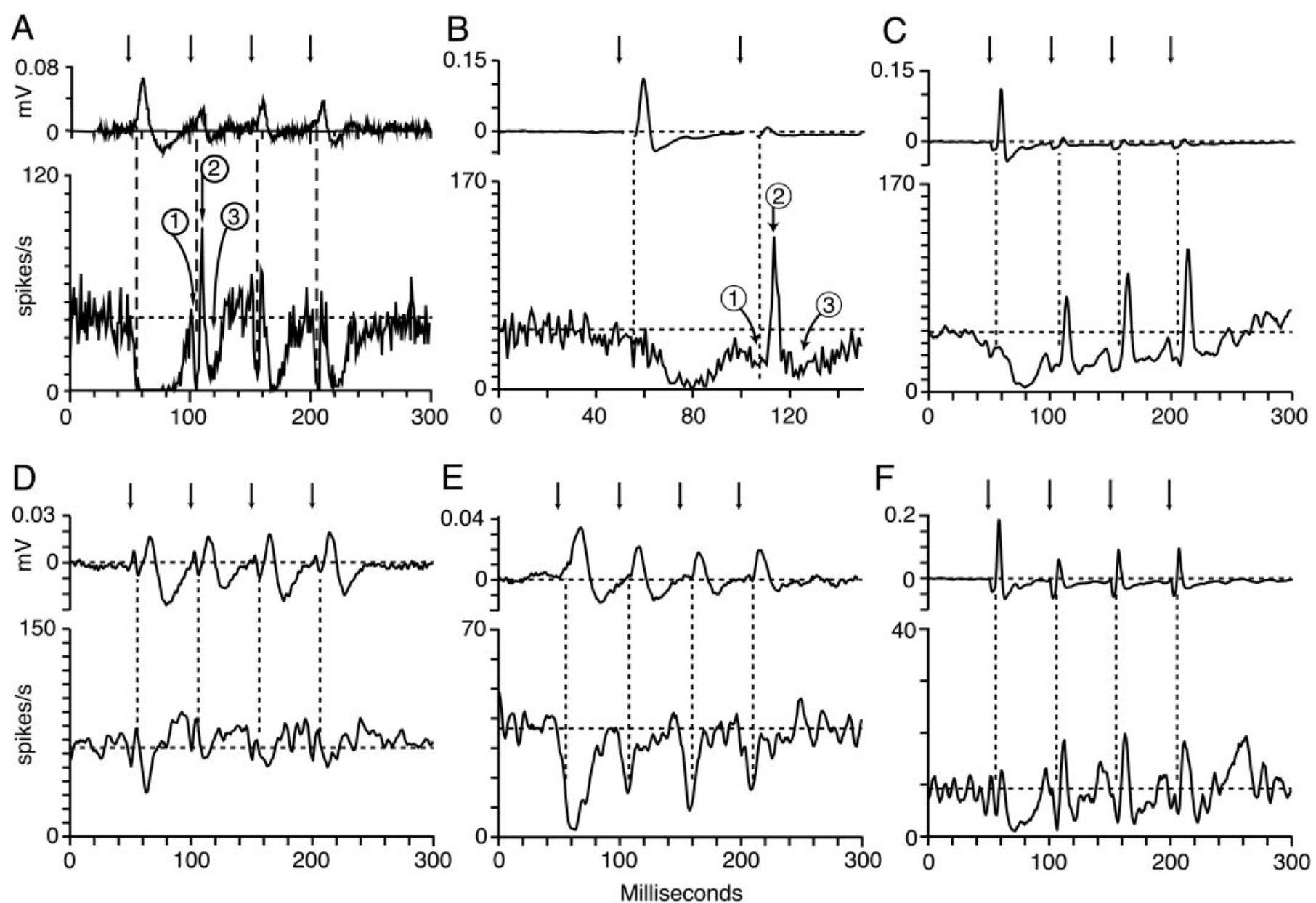

Figure 3. Comparison of the effects on DCN type IV units (principal cells) of electrical stimulation of the MSN and C2. The stimulus consisted of four pulses applied at the times marked by the arrows at the top of each figure. In each plot, the top trace shows the EP at the recording site, and the bottom trace shows the PSTH of single-unit responses to 300-400 stimulus repetitions. No acoustic stimulus was applied, and the horizontal dashed lines in the PSTHs show the mean spontaneous rate. A, Response to stimulation of the MSN (redrawn from Davis and Young, 1997) to show the three components of the response. Components are defined in terms of their timing relative to the onset of the EP (vertical dashed lines) and are labeled with circled numbers: SLI (1), excitation (2), and LLI (3). B, Expanded version of the response to C2 stimulation shown in $C$, with the components labeled as in $A$. Inhibition dominates the response to the first pulse, but all three components can be seen for the second pulse. $C-F$, EP and PSTH traces for four cells from two animals showing responses to $\mathrm{C} 2$ stimulation. EP and PSTH traces were smoothed with a 7 msec wide triangular filter, except for $A$ and $B$.

\section{Which branch of $\mathrm{C} 2$ contributes most to the evoked potential in DCN?}

We stimulated the main branches of $\mathrm{C} 2$ individually $\sim 1 \mathrm{~cm}$ from the spinal cord $(n=6)$. C2 divides into a dorsal (occipitalis major, $\mathrm{C} 2 \mathrm{~d})$ and a ventral $(\mathrm{C} 2 \mathrm{v})$ branch after emerging through the intervertebral foramen (Reighard and Jennings, 1901; Getty, 1975; Abrahams et al., 1984a,b). The main branch of C2d (C2dc) contains muscle and cutaneous components and innervates the caudal part of the pinna, the back of the head, and the rostral dorsal part of the neck. Small branches of C2d innervate neck muscles $(\mathrm{C} 2 \mathrm{dm})$. $\mathrm{C} 2 \mathrm{v}$ divides at the border of the sternocleidomastoid muscle into the large greater auricular nerve (C2vg), innervating the skin and muscles associated with the pinna and a group of smaller branches (transverse cervical nerves). C2v was stimulated proximal to small branches leaving the main trunk. Because $\mathrm{C} 2 \mathrm{vg}$ constitutes the bulk of $\mathrm{C} 2 \mathrm{v}$, we assume that most of the observed EPs are attributable to fibers belonging to C2vg. Indeed, stimulating C2vg near the dorsal pinna gave EPs of the same size as the more proximal stimulation $(n=3$; data not shown). The median EP amplitudes from $\mathrm{C} 2 \mathrm{v}$ and $\mathrm{C} 2$ were similar $(p \sim 0.9)$. The largest EPs were obtained by stimulation of $\mathrm{C} 2 \mathrm{v}$ (Fig. $2 B$ ); stimulation of C2dc resulted in slightly smaller EPs in three cats and much smaller EPs in three others (medians differ; $p<0.001$ ), whereas stimulation of C2dm gave EPs near zero (median different from $\mathrm{C} 2 \mathrm{v} ; p<0.002$ ). Thus, the largest EPs were produced by those branches of $\mathrm{C} 2$ that innervate the pinna and its muscles.

\section{Responses of single units to electrical stimulation of $\mathbf{C 2}$}

The effects of C2 reach the DCN via the MSN (Itoh et al., 1987; Wright and Ryugo, 1996), and the effects of MSN stimulation have been studied previously (Young et al., 1995; Davis et al., 1996). The responses of DCN principal cells to MSN stimulation consist of up to three components. Figure $3 A$ shows an example of MSN stimulation in which all three components are present. The EP onset (vertical dashed lines) is preceded by a short-latency inhibitory component (SLI) (1) and followed by an excitatory peak (2) and a long-latency inhibitory component (LLI) (3). Typically, the excitatory peak is small or nonexistent after the 

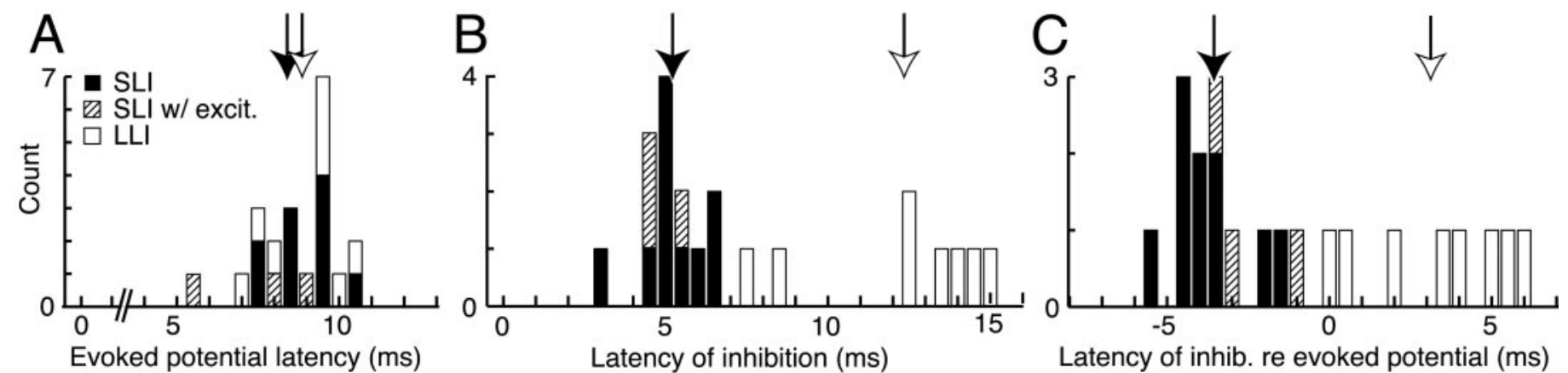

Figure 4. Histograms of the latencies of DCN responses to the first stimulus pulse in response to peripheral stimulation of C2. Consistent with previous results (Davis et al., 1996), latencies were measured from the stimulus pulse to the beginning of the positive-going portion of the EP (EP latency) and to the halfway point in the onset of inhibition (latency of inhibition). The beginning of the EP was defined by eye as the point at which the rapidly rising positive phase of the EP began. Usually, this was easily determined from smoothed EP traces; in noisy cases, it was set at the intersection of the mean prestimulus potential and a line fit to the rising phase of the EP. In units with both SLI and LLI, but without excitation, only the SLI latency can be measured because the transition between the two inhibitory components cannot be reliably observed (e.g., the unit shown in Fig. 3E). LLI and SLI data are represented as shown in the key, with SLI units showing or not showing excitation differentiated by the degree of shading. Open arrows show the mean LLI latency, and filled arrows show the mean SLI latency, regardless of excitation. $A$, Stimulus pulse EP latency. The mean EP latencies are similar for SLI and LLI units $(8.6 \pm 1.2$ vs $8.9 \pm 1.2 \mathrm{msec} ; p>0.5)$ but are significantly longer than with MSN stimulation $(6.6 \pm 0.9$ msec for SLI units and $6.2 \pm$ $0.6 \mathrm{msec}$ for LLI units; both $p<0.01$ ) (Davis et al., 1996 and data not shown). B, Latency of inhibition relative to the stimulus pulse. Both the mean SLI latency $(5.1 \pm 0.9 \mathrm{msec})$ and the mean LLI latency $(12.2 \pm 2.8 \mathrm{msec})$ are significantly increased compared with MSN stimulation $(4.1 \pm 1.9$ msec, $p<0.05$, and $8.6 \pm 2.5 \mathrm{msec}, p<0.01$, respectively). $C$, Latency of inhibition relative to the EP (relative latency of inhibition) computed as the difference between the data in $B$ and $A$. The mean relative latencies of inhibition for SLI units $(-3.5 \pm 1.3 \mathrm{msec})$ and LLI units (3.1 $\pm 2.3 \mathrm{msec})$ are comparable with the values for MSN stimulation $(-2.5 \pm 2.0$ and $2.4 \pm 2.5 \mathrm{msec}$, respectively; both $p>0.1)$.

first stimulus pulse, but the inhibitory components, when present, are seen for all four pulses. With MSN stimulation, the SLI and excitation occur together and are seen in approximately half of the units; the LLI is seen in all responding units and is the only response in the half of the units not showing the SLI and excitation. As before, we assume that the SLI and LLI are two different effects because they can occur separately and because their adaptation characteristics are different (Davis et al., 1996). When the excitatory peak is not present, the SLI and LLI merge together (as for the first pulse in Fig. $3 A$ ). In this paper, an SLI is assumed to be present if the latency of onset of inhibition precedes the EP onset; an LLI is assumed to be present if the inhibition lasts $>5 \mathrm{msec}$.

The EP is thought to reflect the synchronous currents induced in presynaptic and postsynaptic neurons by the parallel fiber volley. The excitatory component represents the direct excitatory input of parallel fibers on principal cells, and the LLI is believed to originate from activation of inhibitory interneurons in the superficial DCN, including cartwheel cells (Davis and Young, 1997, 2000). The origin of the SLI is unknown.

To test whether processing in the MSN changes the responses of DCN cells to somatosensory inputs, we studied the effects of electrical stimulation of C2 on 22 principal cells (19 type IV and three type III units) using the exposed-DCN preparation. Of these 22 neurons, 16 were studied by stimulating C2 proximally close to the ganglion with currents of $50 \mu \mathrm{A}$, and six were studied by stimulating branches of $\mathrm{C} 2$ distally near the pinna with currents of up to $15 \mathrm{~mA}$. All 22 units showed inhibition of spontaneous activity as the principal response to electrical stimulation. The responses to proximal and distal stimulation were quantitatively and qualitatively similar. The mean latency from the distal site was longer $(\sim 1 \mathrm{msec})$, as expected, but the latency difference is not statistically significant, so no distinction is made between the two groups below.

Figure $3 C-F$ illustrates the responses of four units to stimulation of $C 2$. Figure $3 B$ shows an expanded view of the response in Figure $3 C$ to illustrate the three components. All units (22 of 22) showed the LLI, most easily seen in the response to the first pulse in which it is largest (Fig. 3C-F). Thirteen of $22(59 \%)$ units showed the SLI, which is approximately the same size for all four pulses (Fig. 3C,E,F). Only three of $22(14 \%)$ units showed an excitatory peak (Fig. $3 C, F$ ), which followed an SLI in all three cases. The relative proportions of units showing both the SLI and LLI (called SLI units below) versus units showing only the LLI (LLI units) are similar to the MSN results, but significantly fewer units (14 vs 49\%) showed excitation.

\section{The characteristics of the DCN responses to $\mathrm{C} 2$ and MSN stimulation are similar}

The presence of the three response components in both data sets suggests that C2 stimulation activates similar pathways as MSN stimulation. To test this hypothesis, we compared the latency and adaptation properties of the EP and the inhibitory components during $\mathrm{C} 2$ and MSN stimulation. The MSN comparison data were obtained from Davis et al. (1996). One cell from the present study was excluded because its latency of inhibition was $35 \mathrm{msec}$.

We found that the mean EP latencies of SLI and LLI units were $\sim 2$ msec longer with $\mathrm{C} 2$ stimulation than with MSN stimulation (both $p<0.01$ ) (Fig. $4 A$ and its caption). The mean latencies of inhibition for SLI and LLI units were 1 and $3.6 \mathrm{msec}$ longer than with MSN stimulation ( $p<0.05$ and $p<0.01$, respectively) (Fig. $4 B$ and its caption). The increased latencies are consistent with additional peripheral conduction delay and synaptic delay in the MSN. In contrast, the latencies from EP onset to inhibition (relative latencies of inhibition) should reflect events within the DCN only. The mean relative latencies of inhibition of both the SLI and LLI were the same for C2 and MSN stimulation (both $p>0.1$ ) (Fig. $4 C$ and its caption), consistent with the activation of identical inhibitory pathways within DCN from the two stimulus sites.

Previous results showed that, with MSN stimulation, the EP and the LLI are largest at the first pulse of the four-pulse sequence, smallest at the second, and then increase somewhat 

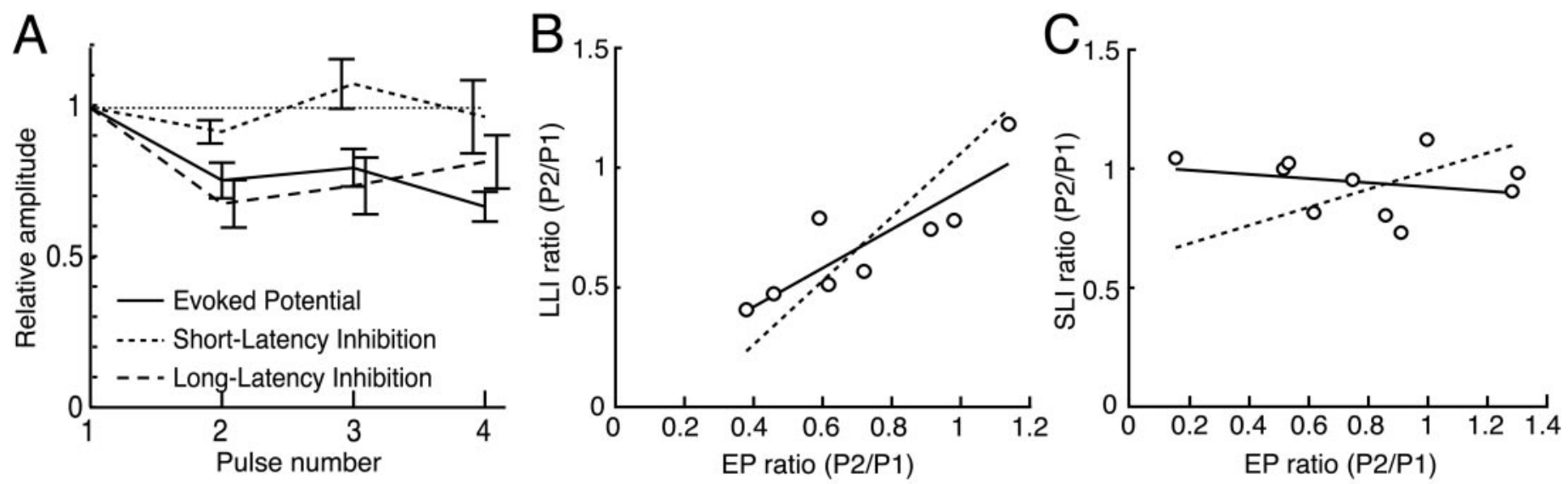

Figure 5. Adaptation of the EP, SLI, and LLI amplitudes during peripheral electrical stimulation of C2. The amplitudes of the SLI and LLI are defined as the differences between the spontaneous rate and the minimum rate during the inhibitory response. When the SLI and LLI were not separated in the first pulse response (see Fig. $3 E$ ), the SLI amplitude was taken at the latency of the SLI peak for the remaining pulses. $A$, The mean amplitudes of the EP, the SLI, and the LLI are plotted for pulses 2-4 relative to the first pulse. Error bars show SEMs for $n=13$ (SLI), 10 (LLI), and 23 (EP). Mean LLI and EP amplitudes, but not SLI amplitude, are significantly smaller at pulse 2 compared with pulse 1 ( $p<0.01, p<0.01$, and $p>0.05$, respectively). The LLI and EP remain significantly below 1 for the third pulse $(p<0.05$ and $p<0.01)$. The EP remains significantly below 1 for the fourth pulse $(p<$ $0.01)$, whereas the LLI does not $(p \sim 0.1)$. The LLI and EP amplitudes do not increase significantly from pulse 2 to pulses 3 and 4 ( $p>0.2)$. B, LLI amplitude ratio as a function of EP amplitude ratio. These ratios are the amplitude in response to the second pulse $(P 2)$ divided by the amplitude in response to the first pulse $(P 1)$. The solid line shows the regression for the data $(y=0.10+0.81 * x ; r=0.86 ; p<0.01)$. The dashed line shows the regression for MSN stimulation $\left(y=-0.27+1.33 * x ; r=0.77 ; p<10^{-6}\right.$; from Davis et al., 1996). $C$, SLI amplitude ratio as a function of EP ratio. The solid line shows the regression for the data $(y=1.01-0.09 * x ; r=0.19$; NS). The dashed line shows the regression for MSN stimulation $(y=0.61$ $+0.38 * x ; r=0.21 ; \mathrm{NS}$; from Davis et al., 1996).

from the second to the fourth pulse. The SLI is slightly weaker at the second pulse compared with the others (Davis et al., 1996).

We measured the amount of inhibition (meaning the decrease in rate at maximal inhibition) for the SLI and LLI and the amplitude of the EP at each of the four pulses in 18 units that did not show saturating inhibition with peripheral stimulation (Fig. $5 A$ ). The LLI (dashed line) and EP (solid line) amplitudes were largest at the first pulse and decreased significantly at pulses $2-4$, except for the LLI at pulse 4, which does not significantly differ from pulse 1. The SLI amplitude (dotted line) did not change significantly through the four pulses. These results differ from the results of MSN stimulation only in that there is no significant increase in LLI and EP amplitude from the second to the fourth pulse.

Figure $5 B$ shows the relative amplitude (second pulse divided by first pulse) of inhibition as a function of the relative EP amplitude for eight cells showing only LLI. A strong association exists between the EP ratio and the inhibitory amplitude ratio (solid line) $(r=0.86 ; p<0.01)$. This relationship is similar to that reported previously for MSN stimulation (dotted line) and supports the hypothesis that the EP and the LLI share a common source. In contrast, little or no association exists between the EP and the SLI $(n=10$ cells; $r=0.19)$ (Fig. $5 C)$, similar to the results with MSN stimulation (dotted line). These results suggest that similar pathways were activated by $\mathrm{C} 2$ and MSN stimulation.

\section{Lack of response to cutaneous stimuli}

In cat, $\mathrm{C} 2$ carries both proprioceptive and cutaneous fibers (Abrahams et al., 1984a,b). To investigate the modality of the somatosensory projection to DCN, we recorded from $47 \mathrm{DCN}$ principal cells and searched for somatosensory stimuli that would excite or inhibit them. The intact-head preparation, with the ipsilateral (left) side of the head intact, was used. We explored the left side of the cat and, based on the above results, paid most attention to

\begin{tabular}{|c|c|c|c|c|}
\hline Stimulus & $\begin{array}{l}\text { Number } \\
\text { tested }\end{array}$ & $\begin{array}{l}\text { Excitatory } \\
\text { response }\end{array}$ & $\begin{array}{l}\text { Inhibitory } \\
\text { response }\end{array}$ & $\begin{array}{l}\text { Both } \\
\text { responses }\end{array}$ \\
\hline Cutaneous stim. & 24 & 0 & 0 & 0 \\
\hline Vibrissa stim. & 24 & 0 & 0 & 0 \\
\hline Move shoulder & 18 & 0 & 2 & 0 \\
\hline Press pinna dorsum & 33 & 0 & 16 & 0 \\
\hline Manual pinna stretch & 26 & 0 & 10 & 0 \\
\hline Sinusoidal pinna stretch & 15 & 0 & 6 & 4 \\
\hline $\begin{array}{l}\text { Sinusoidal pinna stretch } \\
\text { (complex striking) }\end{array}$ & 6 & 4 & 0 & 1 \\
\hline $\begin{array}{l}\text { Muscle vibration } \\
\text { (type IV) }\end{array}$ & 16 & 3 & 6 & 3 \\
\hline $\begin{array}{l}\text { Muscle vibration } \\
\text { (type III) }\end{array}$ & 5 & 3 & 0 & 0 \\
\hline $\begin{array}{l}\text { Muscle vibration } \\
\text { (complex spiking) }\end{array}$ & 1 & 1 & 0 & 0 \\
\hline
\end{tabular}

receptive fields in the areas innervated by $\mathrm{C} 2$ in the head and neck. Fourteen type IV units were unresponsive to any somatosensory stimulus tested.

The first section of Table 1 shows the results of manual testing for cutaneous somatosensory receptive fields in a subpopulation of 24 type IV units. Brushing the skin and hairs, tapping, and stretching the skin on and near the pinna ("Cutaneous stim.") had no effect on the discharge rates. Similarly, moving the vibrissae ("Vibrissa stim.") had no effect. Thus, stimuli likely to drive receptors in the skin that are sensitive to light touch and hair movement were ineffective. Receptive fields on the rest of the body were not observed ( 0 of 10$)$. 
A

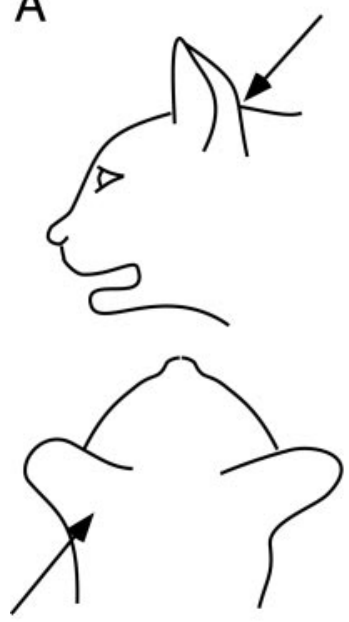

B

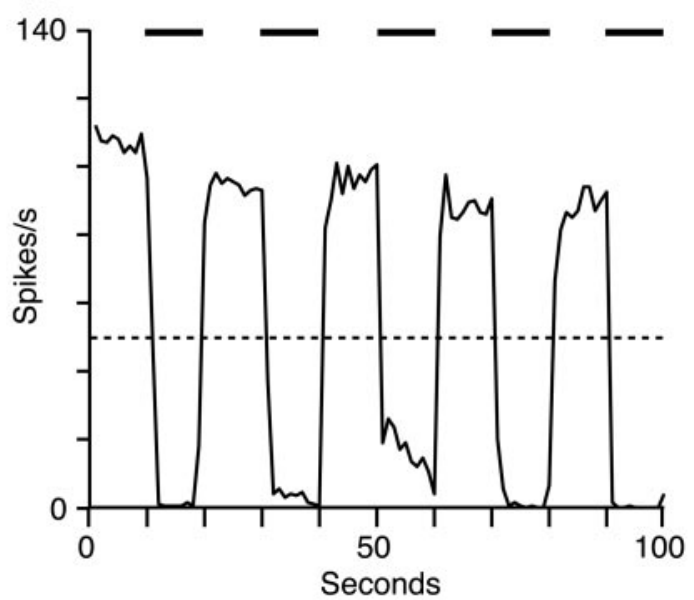

C

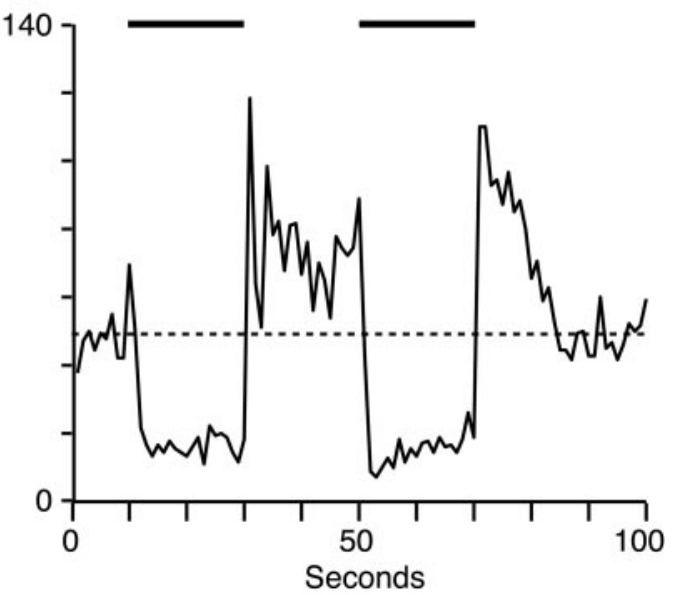

Figure 6. Responses of DCN neurons to stretch of the pinna muscles. $A$, Arrows show the direction and location of pressure manually applied to the scutiform cartilage. $B, C$, Responses of two type IV units (BF of 24.2 and $23.4 \mathrm{kHz}$ ) to manual pressure applied as in $A$. The plots are PSTHs of one repetition of the stimulus made with a bin width of $1 \mathrm{sec}$. Pressure was applied by the experimenter and maintained for $\sim 10 \mathrm{sec}(B)$ and $\sim 20 \mathrm{sec}(C)$, marked by the bars; the actual stimulus waveform was not recorded. The neuron in $B$ was responding to continuous broadband noise $\sim 20 \mathrm{~dB}$ above threshold, and the neuron in $C$ was firing spontaneously. The effect of the pressure was a tonic inhibition, which was maintained as long as the pressure was applied. Horizontal dashed lines show spontaneous rate. The unit in $C$ shows increased firing after release of pressure, possibly attributable to rebound from inhibition or the acoustic effects of the experimenter's hand above the animal's head, because this unit was extremely sensitive to sound.

\section{Responses to deep pressure and muscle stretch}

We next presented stimuli designed to activate deep receptors to a subpopulation of the same set of 47 neurons (Table 1, second section). Shoulder movement relative to the neck ("Move shoulder") caused weak inhibition in 2 of 18 type IV units. The most effective manually applied stimulus was localized pressure, applied by the index finger of the experimenter, to the dorsum of the pinna, approximately above the scutiform cartilage (Fig. 6A; Table 1, Press pinna dorsum). This stimulus inhibited 16 of 33 type IV units; two examples are shown in Figure $6, B$ and $C$. The noise-driven or spontaneous firing of units was inhibited tonically while pressure was applied (bars at the top of the figures).

The scutiform cartilage serves as an attachment point for a group of pinna muscles that are stretched when pressure is applied to the cartilage (Crouch, 1969). Therefore, we pulled the pinna laterally while pressing lightly on the dorsum above the cartilage, which also stretches the pinna muscles (Table 1, Manual pinna stretch). Ten of 26 type IV units were inhibited by this manipulation. Eight of the 10 inhibited neurons were also tested with pressure applied to the pinna dorsum, and all eight were inhibited, as expected if both manipulations stimulate the same peripheral receptor.

To achieve better stimulus control, we performed separate experiments in 15 principal cells (13 type IV and two type III units) and six complex-spiking neurons using a mechanical stimulator to apply repeated lateral stretch to the pinna. For the principal cells, the responses were complex and varied among units. Nevertheless, inhibitory responses predominated and were seen in 10 of 15 cases, either alone or in combination with excitatory responses (Table 1, Sinusoidal pinna stretch). When excitatory responses were present, they occurred as brief peaks after or during extended inhibitory responses in most cases (three of four). Examples of principal cell responses are shown in Figure $7 A-D$. Note the excitatory peaks, indicated by the arrows. Note also that inhibitory responses occur on both phases of the stimulus, best illustrated by the examples in Figure 7, $C$ and $D$, which show the responses of one unit to stimuli of both polarities.
Complex-spiking neurons showed excitatory responses to pinna stretch (five of six) [Table 1, Sinusoidal pinna stretch (complex spiking)], accompanied by inhibition in one case. Examples are shown in Figure $7 E-G$. These are typical in that responses occurred as brief excitatory peaks. The complex spiking responses also occurred on both phases of the stimulus waveform, as illustrated for one unit in Figure $7, F$ and $G$. The examples in the left and right halves of Figure 7 ( $A, B, E$ and $C, D, F, G$, respectively) were recorded in the same electrode track using the same stimuli. Comparing vertically, note the general correspondence between the excitatory peaks in the complex-spiking neurons and the inhibitory responses in principal cells, consistent with the hypothesized inhibitory effect of cartwheel cells on principal cells.

The average latency of excitation for complex-spiking cells and the average latency of inhibition for principal cells to a $10 \mathrm{~Hz}$ stretch were similar (means of $23.6 \pm 5.8$ and $20.6 \pm 5.1 \mathrm{msec}$, respectively; $p>0.2$ ). The latencies are larger than for electrical C2 stimulation, probably because of the latency of the peripheral sensory response. Consistent with the apparent rectification shown in the right half of Figure 7, there was no difference in the mean latencies of inhibition for initially positive and initially negative stimuli for principal cells $(p>0.2)$.

During manual testing for somatosensory receptive fields, care was taken to avoid producing sounds, especially broadband sounds. DCN principal cells are exquisitely sensitive to sounds such as those that are produced by brushing hairs on the pinna or touching the pinna. It was usually easy to determine when a response was acoustic, however, because moving the site of stimulation along the skin or changing the rate of movement could be used to vary independently the somatosensory and auditory stimulation. In some cases (Fig. 6B), masking noise was presented to reduce the audibility of any incidental sounds. Results such as the data shown for type IV units in Figure 7 are unlikely to be auditory artifacts because broadband sounds produced during pinna movements are invariably excitatory for DCN principal cells. It is not possible to make this argument for the complexspiking units, but no acoustic stimulus was apparent to the exper- 


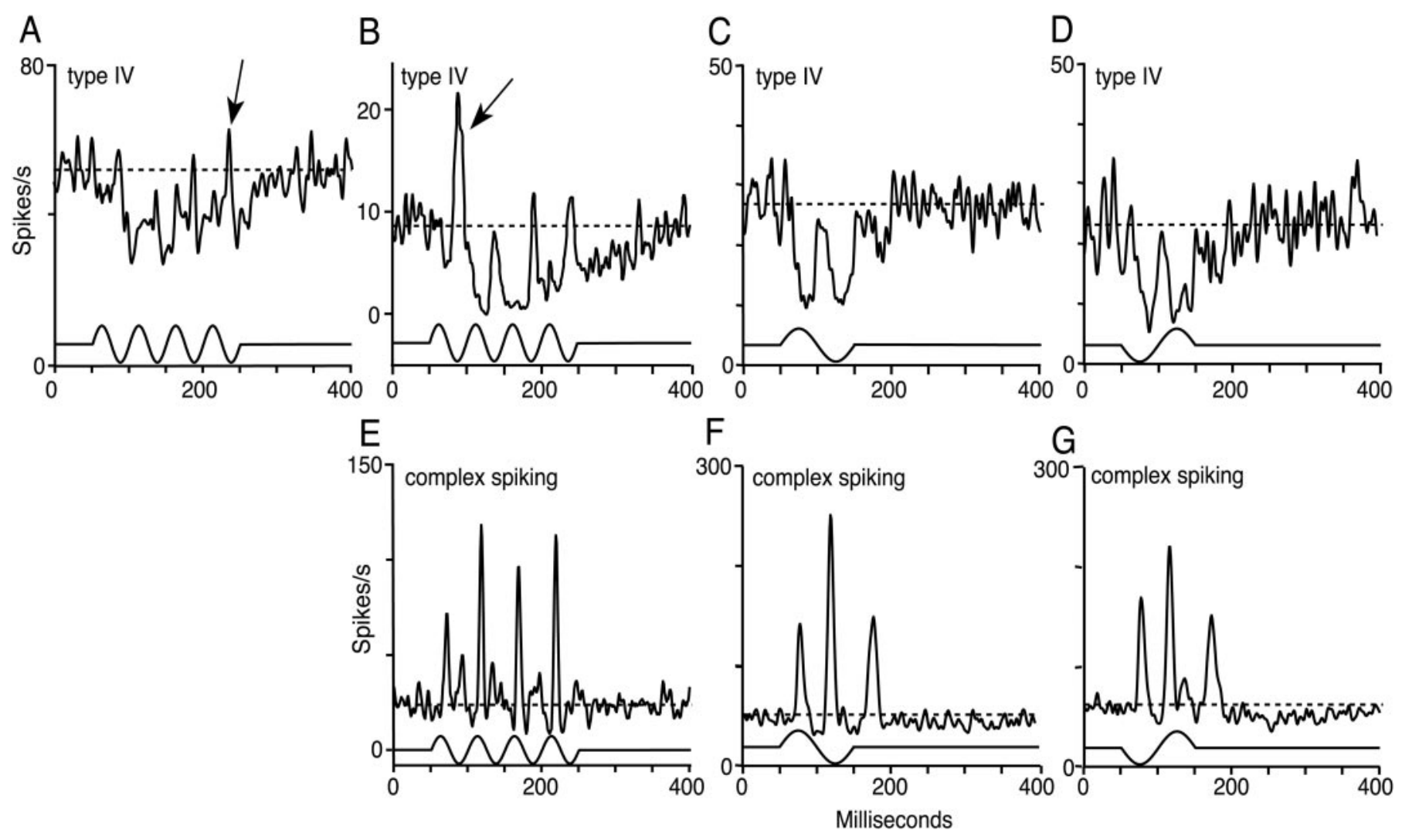

Figure 7. Responses of principal cells and complex-spiking neurons to sinusoidal pinna stretch. The top trace in each plot shows the PSTH of responses to 200-600 repetitions of the pinna-stretch waveform shown in the bottom trace. The zero and the scale of the bottom (stimulus) trace are arbitrary. Upward in the bottom trace is lateral stretch of the pinna muscles. Horizontal dashed lines in the PSTH show spontaneous rate. The zero of the top (PSTH) trace is sometimes offset to separate the traces. $A-D$, Responses of three type IV units ( $C$ and $D$ are the same unit with different stimulus polarities). Arrows in $A$ and $B$ point to excitatory peaks. $E-G$, Responses of two complex-spiking neurons ( $F$ and $G$ are the same unit with different stimulus polarities). Units in $A, B, E$ and in $C, D, F, G$ are each from the same track and received the same stimulus (different tracks from different experiments in the two groups). BFs are as follows: $A, 14.7 \mathrm{kHz} ; B, 18.5 \mathrm{kHz} ; C, D, 23.7 \mathrm{kHz} ; E, 17.3 \mathrm{kHz} ; F, G, 25.3 \mathrm{kHz}$.

imenters in these cases and complex-spiking cells are less sensitive to acoustic stimuli than are principal cells (Davis and Young, 2000).

\section{Response to vibration}

The results in Table 1 and Figures 6 and 7 suggest involvement of deep receptors associated with the pinna muscles, such as muscle spindles or tendon organs. Because muscle spindles are sensitive to vibration at frequencies of $50-300 \mathrm{~Hz}$ (Echlin and Fessard, 1938; Kuffler et al., 1951; Granit and Henatsch, 1956; Bianconi and Van Der Meulen, 1963; Crowe and Matthews, 1964), the effects of vibratory stimuli applied to the dorsum of the pinna at a position overlying musculus auricularis superioris were studied in 22 DCN units (16 type IV, five type III, and one complexspiking). Type IV units showed both inhibitory and excitatory responses to vibration, whereas type III units and the complexspiking unit showed excitation (Table 1, bottom).

Figure $8 A$ shows the response area (rate vs vibration frequency) of a type IV unit in which only inhibition was observed. The poststimulus time histogram (PSTH) of the response to application of $80 \mathrm{~Hz}$ vibration (Fig. $8 \mathrm{~B}$ ) shows that the unit was inhibited tonically during the vibration. Figure $8 C$ shows the response area of a second type IV unit that was inhibited by vibration up to $180 \mathrm{~Hz}$ and excited by higher frequencies. The PSTH of the response to $70 \mathrm{~Hz}$ vibration (Fig. 8D) shows that the response of this unit was phase locked to the stimulus waveform but was still predominantly inhibitory. The mean latency to the onset of inhibition with vibratory stimuli was $19.1 \pm 5.8 \mathrm{msec}$, similar to the latencies obtained with pinna stretch $(p>0.1)$, suggesting that the same receptors were stimulated.

The two units shown in Figure 8 were excited by noise stimuli and had BFs of 53.0 and $52.0 \mathrm{kHz}$, so it is unlikely that the inhibition arose from acoustic artifacts. Moving the stimulus probe away from the muscle along the skull abolished the effects of vibration on the three DCN units tested (data not shown).

The vibration frequency giving the strongest inhibitory response in type IV units ranged from 70 to $320 \mathrm{~Hz}$, with a median of $110 \mathrm{~Hz}(n=8)$, consistent with activation of muscle spindles. The vibration frequencies giving the strongest excitatory response in type III and type IV units were similar $(80 \mathrm{~Hz}, n=3$, and 78 $\mathrm{Hz}, n=7$, respectively; $p>0.5)$. The strongest response frequencies for inhibitory and excitatory responses in type IV units were different $(p<0.01)$, suggesting that they might reflect different modes of peripheral response or different receptors.

\section{DISCUSSION}

\section{Peripheral source of the somatosensory input}

Our data show that the largest EPs in DCN result from stimulating the greater auricular $(\mathrm{C} 2 \mathrm{vg})$ and occipitalis major $(\mathrm{C} 2 \mathrm{~d})$ branches of $\mathrm{C} 2$, suggesting that these branches are the source of the largest somatosensory projection to DCN. These branches of 


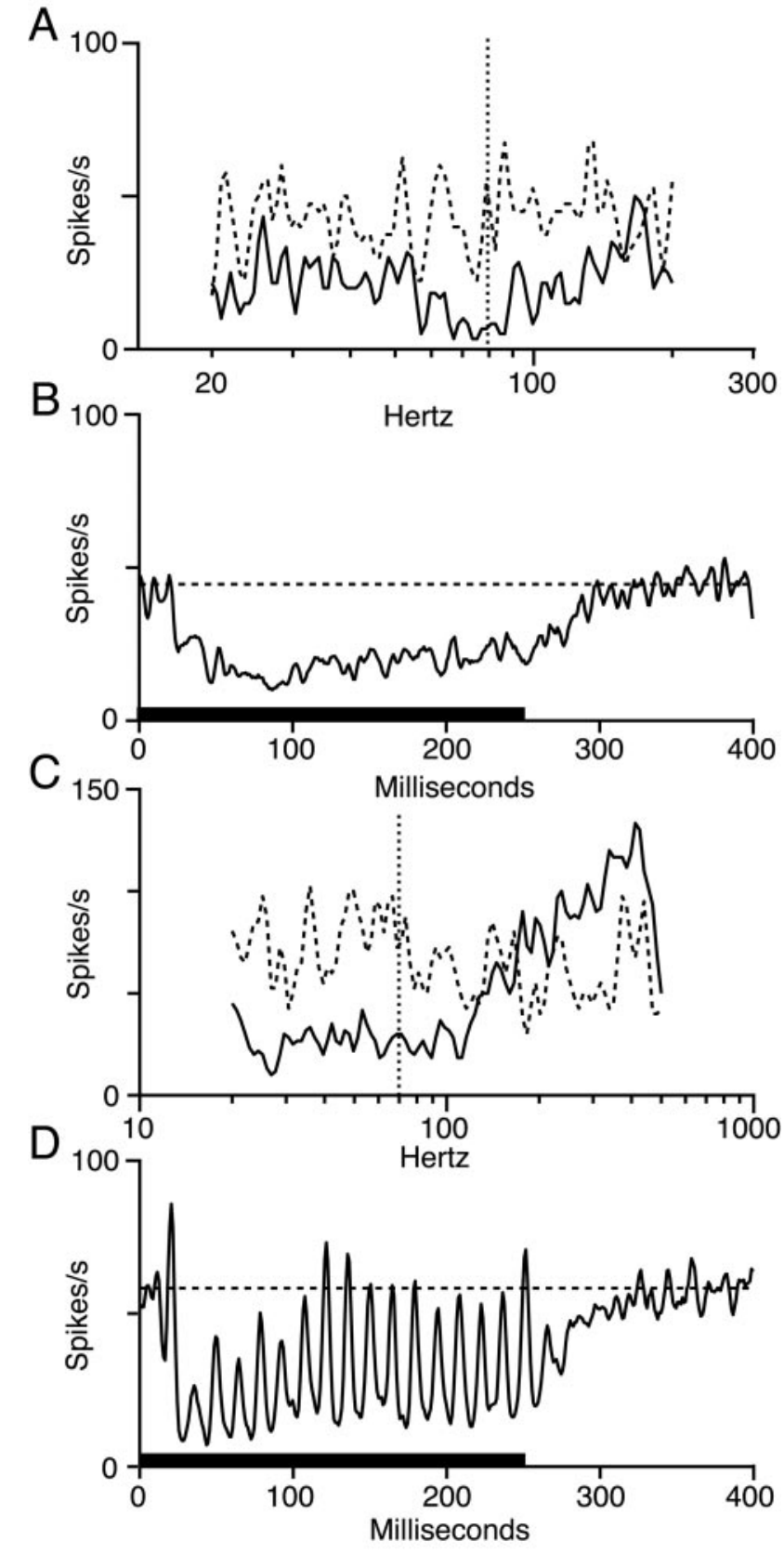

Figure 8. Responses of DCN type IV units to vibration applied to the belly of the muscle that pulls the pinna medially (musculus auricularis superioris). $A$, Average discharge rate during the $250 \mathrm{msec}$ vibratory stimulus plotted versus stimulus frequency. Solid line is rate during the vibration; dashed line is spontaneous rate during the $375 \mathrm{msec}$ immediately preceding the stimulus. Vertical dashed line is at $80 \mathrm{~Hz}$, the stimulus frequency of the response shown in $B$. Stimuli were presented once per second; each frequency was presented once. $B$, PSTH of 300 repetitions of an $80 \mathrm{~Hz}$ stimulus, same unit as in $A$. Heavy line on the abscissa shows the stimulus duration. $C, D$, Same as $A$ and $B$, except for a different unit. $D$ is the response to 300 repetitions of a $70 \mathrm{~Hz}$ stimulus (dashed line in $C$ ).

C2 innervate most of the cat pinna (Abrahams et al., 1984a). These results are consistent with previous findings that stimulation at pinna sites in the MSN somatotopic map is most effective in producing EPs or driving units in DCN (Young et al., 1995).

Stimulation of peripheral nerves other than C2 and of nonpinna sites in MSN (Young et al., 1995) resulted in weaker effects in the DCN. Thus, although the primary projection to the DCN is from the pinna, it is clear that the DCN receives projections from other parts of the body. Despite the EP evidence for nonpinna projections, we observed few DCN neurons with receptive fields outside of the pinna region, suggesting that nonpinna projections are weak, difficult to drive with somatosensory stimuli, or ineffective in driving DCN neurons. Stimulation of C7 and C8 produced the largest EPs outside of C2. These nerves innervate neck and forelimb muscles, so their inputs might be related to posture or movement of the head relative to the forelimbs and body. The weak inhibition produced by moving the shoulder in two cases is consistent with this hypothesis. However, receptive fields related to posture cannot reliably be tested in our preparation and thus were not systematically studied.

Small EPs were observed with stimulation of part of the trigeminal nerve that innervates the rostral pinna and adjacent areas of the face, including the vibrissae (Reighard and Jennings, 1901; Getty, 1975). This is consistent with previous results showing that stimulating the vibrissa region of the MSN produced large EPs in DCN (Young et al., 1995). However, we did not observe neural responses to vibrissa movement in this study. There are three possible explanations for the difference. First, in our previous study, it was difficult to map the face region accurately because of the surgical preparation, so what appeared to be vibrissa responses may not have been. Second, the cutaneous branch of $\mathrm{C} 2$ sends a small fiber bundle ventrolateral to the main cuneate nucleus, which terminates in the trigeminal nucleus (Abrahams et al., 1984b) at a site consistent with the somatotopic representation of the vibrissae (Millar and Basbaum, 1975). Perhaps this fiber bundle was stimulated in our previous study. Third, receptive fields of cuneate neurons can change rapidly, within minutes to hours, after damage to peripheral nerves $(\mathrm{Xu}$ and Wall, 1997, 1999). Thus, surgical damage in our previous study could have triggered a reorganization that produced vibrissa responses in previous pinna areas.

In previous work, the pinna sites that produced large DCN EPs were not characterized in terms of deep versus cutaneous sensitivity (Young et al., 1995). However, those sites usually responded strongly to cutaneous stimuli, and, in placing the stimulating electrodes in MSN, cutaneous responses from the pinna were used. Those results are not at odds with the present results, however, because both cutaneous and muscle afferents from C2 synapse in the main cuneate nucleus (Abrahams et al., 1984b). There, cutaneous and proprioceptive neurons are intermingled, and some cuneate neurons respond to both stimulus modalities (Rosen, 1969a,b; Rosen and Sjolund, 1973; Millar, 1979; Dykes et al., 1982; Surmeier and Towe, 1987). Thus, electrical stimulation in a region of MSN giving cutaneous responses probably activates proprioceptive as well as cutaneous neurons.

\section{Neural responses to peripheral electrical stimulation}

The responses to electrical stimulation of C2 were mostly similar to those obtained by electrical MSN stimulation (Davis et al., 1996), suggesting that the DCN is activated in the same way in both cases and that synaptic processing in MSN has little effect on DCN responses to the stimuli used here. The largest difference between the two stimulus sites is that few SLI units showed excitation with $\mathrm{C} 2$ stimulation, whereas excitation was present in almost all SLI units with MSN stimulation. The excitation is weak even with MSN stimulation and seems often to be overwhelmed by the inhibitory components (e.g., in the response to the first pulse in a four-pulse sequence). Thus, the reduced excitation could be attributable to minor differences between C2 and MSN 
stimulation, such as a reduced synchrony of the afferent excitatory volley in DCN with $\mathrm{C} 2$ stimulation because a more diverse set of pathways is activated.

The presence of SLI after stimulation of C2 rules out one hypothesis for the origin of the SLI: that it is caused by antidromic activation of inhibitory DCN neurons that also project to the MSN (Davis et al., 1996). Such neurons are unlikely to be activated in the same way by peripheral electrical stimulation. Other than this, the present results do not add to the previously defined characteristics of the SLI source: that it is glycinergic (Davis and Young, 2000), that it has a rapid conduction velocity from the MSN to the DCN, and that it is organized in such a way that it does not produce an EP in the DCN.

\section{Neural responses to somatosensory stimulation}

The responses to pinna stretch and muscle vibration are generally consistent with the electrical stimulation results in that the predominant response in principal cells was inhibitory and the predominant response in complex-spiking cells was excitatory. The observation most difficult to explain is the finding of net excitatory responses to muscle vibration in some units (Fig. $8 \mathrm{C}$ at frequencies above $180 \mathrm{~Hz}$ ). Previously, all somatosensory stimuli, whether electrical or natural, have produced predominantly inhibitory responses in principal cells. Two mechanisms could account for these excitatory responses. First, inhibitory inputs to principal cells could adapt more strongly to vibration than excitatory inputs. With four-pulse electrical stimulation, the excitatory responses generally increase in amplitude from the first to the second pulse, whereas the LLI decreases, often dramatically (Fig. 3D,E). Thus, the inhibitory input could weaken substantially during the vibratory stimulus, without a change in excitatory input. Figure $8 D$ is consistent with this hypothesis in that the excitatory peaks increase in amplitude during the first $100 \mathrm{msec}$ of the response. Second, the activation pattern of parallel fibers might be different between electrical stimulation and muscle vibration. Electrical stimulation leads to massive synchronous activation of parallel fibers, evident from the large EP. On the other hand, vibration of one or a few muscles might cause a patterned activation of a small subset of parallel fibers. The nature of the mapping of individual muscles onto the parallel fibers is not known. If, by analogy to the fractured somatotopic representation in the cerebellum (Shambes et al., 1978a,b; Kassel et al., 1984), pinna muscles project in a patterned way onto the DCN, then it is possible that a particular muscle produces either excitatory or inhibitory effects on a particular DCN principal cell, although the overall effect of mass activation is inhibitory.

\section{Functional implications of pinna input for the role of the DCN}

The result that the $\mathrm{DCN}$ receives proprioceptive information from the pinna suggests that the DCN might be involved in coordinating information about the direction in space from which sounds originate with somatosensory information about the direction in which the pinna points. Support for this general hypotheses is provided by the difficulties that cats have in orienting to sound sources after lesions of the DCN (Sutherland et al., 1998; May, 2000). The DCN projects to the inferior colliculus (Oliver, 1984) but also to nonauditory structures, such as the caudal pontine reticular nucleus (Lingenhöhl and Friauf, 1994), a structure implicated in auditory startle (Meloni and Davis, 1998). One functional role of the DCN could be to generate an "error signal" to correct for changes in stimulus spectrum, especially spectral sound-localization information attributable to pinna movements. This information is important in an animal like the cat with a mobile pinna, because the acoustic sound-localization cues change as the pinna moves (Young et al., 1996). Another role of the DCN might be to coordinate pinna movements toward sound sources to optimize auditory perception. Auditory-evoked pinna movements must come partly from a subcollicular auditory source, because cats make initial pinna movements in response to auditory targets $\sim 200 \mathrm{msec}$ before making simultaneous pinna and eye movement toward the target (Populin and Yin, 1998). The later simultaneous pinna and eye movements, which are also seen with visual targets, are thought to originate in the superior colliculus. We therefore hypothesize that the DCN could be a source of the early orientation response.

It has also been suggested that the somatosensory input to the DCN could be a substrate for the clinical phenomenon of somatic (craniocervical) tinnitus, in which movements of joints or muscles, especially in the head and neck, modulate tinnitus (Levine, 1999). The tinnitus effects resemble those described here in that they involve deep, as opposed to cutaneous, somatosensory modalities, and they seem to be associated with the head and neck as opposed to the extremities.

The results presented here clarify one aspect of DCN processing by showing that the somatosensory input to the $\mathrm{DCN}$ is specifically associated with pinna muscles and not with other sensory information about the pinna. However, it raises new questions, perhaps the most interesting of which is the nature of the mapping of pinna muscles onto the parallel fiber array in superficial DCN.

\section{REFERENCES}

Abrahams VC, Lynn B, Richmond FJ (1984a) Organization and sensory properties of small myelinated fibres in the dorsal cervical rami of the cat. J Physiol (Lond) 347:177-187.

Abrahams VC, Richmond FJ, Keane J (1984b) Projections from C2 and C3 nerves supplying muscles and skin of the cat neck: a study using transganglionic transport of horseradish peroxidase. J Comp Neurol 230:142-154.

Bianconi R, Van Der Meulen JP (1963) The response to vibration of the end organs of mammalian muscle spindles. J Neurophysiol 26:177-190.

Crouch JE (1969) Text-atlas of cat anatomy. Philadelphia: Lea \& Febiger.

Crowe A, Matthews PBC (1964) Further studies of static and dynamic fusimotor fibres. J Physiol (Lond) 174:132-151.

Davis KA, Young ED (1997) Granule cell activation of complex-spiking neurons in dorsal cochlear nucleus. J Neurosci 17:6798-6806.

Davis KA, Young ED (2000) Pharmacological evidence of inhibitory and disinhibitory neural circuits in dorsal cochlear nucleus. J Neurophysiol 83:926-940.

Davis KA, Miller RL, Young ED (1996) Effects of somatosensory and parallel-fiber stimulation on neurons in dorsal cochlear nucleus. J Neurophysiol 76:3012-3024.

Dykes RW, Rasmusson DD, Sretavan D, Rehman NB (1982) Submodality segregation and receptive-field sequences in cuneate, gracile, and external cuneate nuclei of the cat. J Neurophysiol 47:389-416.

Echlin F, Fessard A (1938) Synchronized impulse discharges from receptors in the deep tissues in response to a vibrating stimulus. J Physiol (Lond) 93:312-334.

Getty R (1975) The anatomy of domestic animals. Philadelphia: Saunders.

Granit R, Henatsch HD (1956) Gamma control of dynamic properties of muscle spindles. J Neurophysiol 19:356-366.

Hekmatpanah J (1961) Organization of tactile dermatomes, C1 through L4 in cat. J Neurophysiol 24:129-140.

Itoh K, Kamiya H, Mitani A, Yasui Y, Takada M, Mizuno N (1987) Direct projection from the dorsal column nuclei and the spinal trigeminal nuclei to the cochlear nuclei in the cat. Brain Res 400:145-150.

Kassel J, Shambes GM, Welker W (1984) Fractured cutaneous projections to the granule cell layer of the posterior cerebellar hemisphere of the domestic cat. J Comp Neurol 225:458-468.

Kuffler SW, Hunt CC, Quilliam JP (1951) Function of medullated smallnerve fibers in mammalian ventral roots: efferent muscle spindle innervation. J Neurophysiol 14:29-54. 
Levine RA (1999) Somatic modulation appears to be a fundamental attribute of tinnitus. In: Proceedings of the sixth international tinnitus seminar (Hazell J, ed), pp 193-197. Cambridge, UK: British Society of Audiology.

Lingenhöhl K, Friauf E (1994) Giant neurons in the rat reticular formation: a sensorimotor interface in the elementary acoustic startle circuit? J Neurosci 14:1176-1194.

Manis PB, Spirou GA, Wright DD, Paydar S, Ryugo DK (1994) Physiology and morphology of complex spiking neurons in the guinea pig dorsal cochlear nucleus. J Comp Neurol 348:261-276.

May BJ (2000) Role of the dorsal cochlear nucleus in the sound localization behavior of cats. Hearing Res 148:74-87.

Meloni EG, Davis M (1998) The dorsal cochlear nucleus contributes to a high intensity component of the acoustic startle reflex in rats. Hearing Res 119:69-80.

Millar J (1979) Convergence of joint, cutaneous and muscle afferents onto cuneate neurons in cat. Brain Res 175:347-350.

Millar J, Basbaum AI (1975) Topography of the projection of the body surface of the cat to cuneate and gracile nuclei. Exp Neurol 49:281-290.

Musicant AD, Chan JCK, Hind JE (1990) Direction-dependent spectral properties of cat external ear: new data and cross-species comparisons. J Acoust Soc Am 87:757-781.

Oliver DL (1984) Dorsal cochlear nucleus projections to the inferior colliculus in the cat: a light and electron microscopic study. J Comp Neurol 224:155-172.

Populin LC, Yin TCT (1998) Pinna movements of the cat during sound localization. J Neurosci 18:4233-4243.

Reighard J, Jennings HS (1901) Anatomy of the cat, Ed 2. New York: Holt.

Rice JJ, May BJ, Spirou GA, Young ED (1992) Pinna-based spectral cues for sound localization in cat. Hearing Res 58:132-152.

Rosen I (1969a) Afferent connexions to group I activated cells in the main cuneate nucleus of the cat. J Physiol (Lond) 205:209-236.

Rosen I (1969b) Localization in caudal brain stem and cervical spinal cord of neurones activated from forelimb group I afferents in the cat. Brain Res 16:55-71.

Rosen I, Sjolund B (1973) Organization of group I activated cells in the main and external cuneate nuclei of the cat: identification of muscle receptors. Exp Brain Res 16:221-237.
Saadé NE, Frangieh AS, Atweh SF, Jabbur SJ (1989) Dorsal column input to cochlear neurons in decerebrate-decerebellate cats. Brain Res 486:399-402.

Shambes GM, Beermann DH, Welker W (1978a) Multiple tactile areas in cerebellar cortex: another patchy cutaneous projection to granule cell columns in rats. Brain Res 157:123-128.

Shambes GM, Gibson JM, Welker W (1978b) Fractured somatotopy in granule cell tactile areas of rat cerebellar hemispheres revealed by micromapping. Brain Behav Evol 15:94-140.

Spirou GA, May BJ, Wright DD, Ryugo DK (1993) Frequency organization of the dorsal cochlear nucleus in cats. J Comp Neurol 329:36-52

Surmeier DJ, Towe AL (1987) Properties of proprioceptive neurons in the cuneate nucleus of the cat. J Neurophysiol 57:938-961.

Sutherland DP, Masterton RB, Glendenning KK (1998) Role of acoustic striae in hearing: reflexive responses to elevated sound-sources. Behav Brain Res 97:1-12.

Weinberg RJ, Rustioni A (1987) A cuneocochlear pathway in the rat. Neuroscience 20:209-219.

Wright DD, Ryugo DK (1996) Mossy fiber projections from the cuneate nucleus to the dorsal cochlear nucleus of rat. J Comp Neurol 365:159-172

Xu J, Wall JT (1997) Rapid changes in brainstem maps of adult primates after peripheral injury. Brain Res 774:211-215.

Xu J, Wall JT (1999) Evidence for brainstem and supra-brainstem contributions to rapid cortical plasticity in adult monkeys. J Neurosci 19:7578-7590.

Young ED (1980) Identification of response properties of ascending axons from dorsal cochlear nucleus. Brain Res 200:23-38.

Young ED, Davis KA (2001) Circuitry and function of the dorsal cochlear nucleus. In: Integrative functions in the mammalian auditory pathway (Oertel D, Popper AN, Fay RR, eds). New York: Springer, in press.

Young ED, Nelken I, Conley RA (1995) Somatosensory effects on neurons in dorsal cochlear nucleus. J Neurophysiol 73:743-765.

Young ED, Rice JJ, Tong SC (1996) Effects of pinna position on headrelated transfer functions in the cat. J Acoust Soc Am 99:3064-3076.

Zhang S, Oertel D (1993) Cartwheel and superficial stellate cells of the dorsal cochlear nucleus of mice: intracellular recordings in slices. J Neurophysiol 69:1384-1397. 